\title{
Melhor idade, ou naturalização da velhice e produção de preconceitos?
}

\section{Better age, or naturalization of old age and production of prejudices?}

\section{¿Mejor edad, o naturalización de la vejez y producción de prejuicios?}

\author{
Renata de Almeida Vieira ${ }^{1}$ \\ Lizete Shizue Bomura Maciel²
}

DOI: http://dx.doi.org/10.20435/serie-estudos.v25i54.1303

\begin{abstract}
Resumo: Este artigo, de natureza bibliográfica, é originário de uma pesquisa maior voltada para a temática preconceito. Seu objetivo é apresentar uma discussão sobre a naturalização da velhice e a produção do preconceito ao idoso. Trata-se de uma discussão sobre a velhice para além das aparências, já que esta vem sendo convertida, desde a terça última parte do século XX, em um nicho de mercado a ser explorado, de modo que os holofotes direcionados aos idosos não são gratuitos nem fortuitos. Mediante o resultado do estudo, destaca-se, entre outras considerações, que o envelhecimento como processo biológico, como alteração de algumas funções orgânicas e como parte do desenvolvimento natural do ser humano é real, está posto para todos os membros da espécie e não há como negá-lo. No entanto a velhice com caráter negativo, carregada de preconceitos, é fenômeno social, logo, uma produção humana, erigida no interior das relações sociais. Discuti-la de tal perspectiva torna-se, portanto, imperioso, se de fato primamos pela promoção humana em todas as suas idades e etapas do desenvolvimento.
\end{abstract}

Palavras-chave: velhice; preconceito; teoria histórico-cultural.

Abstract: This article, of a bibliographic nature, arises from an investigation centered on the subject of prejudice. It aims to present a discussion on the naturalization of old age and the production of prejudices to the elderly. It is a discussion about old age beyond appearances, since this has become, since the third part of the 20th century, a niche market to explore, hence the focus on the elderly is not free or fortuitous. The result of the study, among other considerations, is that aging as a biological process, as an alteration of some organic functions and as part of the natural development of the human being is real, applies to all members of the species, and there is no denying it. However, old age with a negative character, full of prejudices, is a social phenomenon, in consequence, a human production, erected within social relations. Discussing it from that

\footnotetext{
1 Instituto Federal de São Paulo (IFSP), São Paulo, São Paulo, Brasil.

2 Universidade Estadual de Maringá (UEM), Maringá, Paraná, Brasil.
} 
perspective becomes, therefore, imperative if, in fact, we opt for human promotion in all its ages and stages of development.

Keywords: old age; prejudice; cultural-historical theory.

Resumen: Este artículo, de naturaleza bibliográfica, surge de una investigación centrada en la temática del prejuicio. Su objetivo es presentar una discusión sobre la naturalización de la vejez y la producción de prejuicios a los ancianos. Se trata de una discusión sobre la vejez más allá de las apariencias, ya que esta se ha convertido, desde la tercera última parte del siglo XX, en un nicho de mercado para explorar, así que el foco hacia los ancianos no es gratuito ni fortuito. El resultado del estudio, entre otras consideraciones, es que el envejecimiento como proceso biológico, como una alteración de algunas funciones orgánicas y como parte del desarrollo natural del ser humano es real, se aplica a todos los miembros de la especie y no hay como negarlo. Sin embargo, la vejez con un carácter negativo, lleno de prejuicios, es un fenómeno social, en consecuencia, una producción humana, erigida dentro de las relaciones sociales. Discutirlo desde tal perspectiva se vuelve, por lo tanto, imperativo, si de hecho nos decantamos por la promoción humana en todas sus edades y etapas de desarrollo.

Palabras clave: vejez; prejuicio; teoría histórico-cultural.

\section{ESBOÇO DE UM CENÁRIO: IDOSO/VELHICE E PRECONCEITO}

Com o fito de apresentar uma discussão sobre a velhice, a sua naturalização e o preconceito dela decorrente, discussão esta que compõe recorte de um estudo mais amplo, de caráter bibliográfico e exploratório acerca da produção social do preconceito como objetivação humana (VIEIRA, 2011, 2012, 2016), trazemos à baila ambiguidades que envolvem o tema da velhice, assim como o preconceito que pulula em relação à determinada "categoria" de idoso.

Abordar a questão do preconceito ao idoso, na atualidade, não dispensa esboçar, em linhas gerais, elementos do cenário paradoxal no qual ele é engendrado.

Importa marcar, desse cenário, o extraordinário aumento do domínio do homem sobre a natureza, traduzido em avanços científicos e tecnológicos sem paralelo na história humana. Tais avanços trazem, em seu bojo, algumas possibilidades: prolongamento da vida humana com mais qualidade; melhor alimentação e saúde; cura para uma infinidade de enfermidades; prevenção de epidemias e endemia. Enfim, parece que todas elas são oportunidades de promoção humana. Mas de fato são?

Não obstante todo esse potencial para a promoção humana, contraditoriamente, o que vem se efetivando de modo concreto, de modo extensivo, é o acesso restrito às maravilhas produzidas, é a miséria aprofundada e amplificada, 
partilhada entre milhares de seres humanos que, de forma concomitante, produzem preconceitos em antigas e novas roupagens.

A sociedade das mercadorias e dos mercadores, regida pelos ditames do imediato, do instantâneo, do novo, da novidade, do relativo, do produtivo, do competitivo, do transitório, do descartável, da aparência - a despeito do conteúdo -, das relações superficiais, do consumo perdulário, submete, de modo mais ou menos intenso, todos os indivíduos, independentemente da idade, mas sobremaneira o idoso, aquele que se encontra na velhice, na terminalidade da vida.

É sob essa lógica social que se imprime ao indivíduo idoso e à velhice o selo de anacrônico. A figura do idoso é comumente associada ao avesso do criativo, do produtivo, da vitalidade, da virilidade, da força, da beleza, da rapidez, do ágil, como se ele fosse uma espécie de negação do próprio homem. Configura-se como o contrário de tudo que seja valorizado no momento presente - talvez até pela sua permanência, pela duração de sua existência menos afetada e contaminada pelo consumo desnecessário.

A respeito desse último aspecto, concordamos com o que assinalam Maciel e Taam (2007, p. 58, grifo nosso), na discussão que desenvolvem sobre a velhice como espetáculo, isto é, "a sociedade olha seus idosos de forma preconceituosa, acreditando e fazendo-os acreditar que de fato são improdutivos e inúteis".

A realidade, com efeito, expõe Maciel e Taam (2007, p. 58), oferecendo-nos evidências de "[...] que, com o passar dos anos, o vigor, a força física e a rapidez dos reflexos decaem" e as "[...] pessoas em uma idade avançada possuem uma probabilidade maior de ficarem doentes e levam mais tempo para se recuperar". Todavia, ressalvam as autoras, "mesmo sendo um dado de realidade, isto não é necessariamente sinônimo de incapacidade, significando apenas uma possível queda em seu rendimento, em determinadas esferas de ação".

De modo semelhante, Bock (2004, p. 39, grifo nosso), em sua discussão sobre a adolescência, também afirma que há em nossa cultura a valorização do adulto produtivo e a desvalorização de "[...] todas as outras fases da vida: a infância, a velhice e a adolescência, tomadas como fases improdutivas para a sociedade, por isso desvalorizadas".

Essas formas de tratamento e de denominações, no Brasil, são analisadas por Minayo (2003, p. 784) como de violência aos idosos, isto é, "[...] as violências contra a geração a partir dos 60 anos se expressam em tradicionais formas de 
discriminação, como o atributo que comumente lhes é impingido como 'descartáveis' e 'peso social'".

O anacronismo atribuído ao indivíduo idoso vem acompanhado, desde muito tempo, de um tom decadente e pejorativo. Evidência disso são os termos empregados no cotidiano para designar uma pessoa idosa.

\section{O SIGNIFICADO NEGATIVO DE VELHICE NO COTIDIANO}

Por contemplar o uso comum do termo idoso que vige no cotidiano, trazemos aquilo que nos apresenta o léxico a propósito dessa palavra e dos termos correlatos.

Vejamos, primeiramente, o que nos apresenta um dicionário analógico da língua portuguesa, publicado pela primeira vez nos anos de 1950, de autoria de Azevedo (1974). Em que pese a extensão da citação que utilizamos, cremos que seja interessante trazê-la neste estudo, até para entendermos como nós, seres humanos, produzimos significados de acordo com o momento histórico.

Em tal dicionário, Azevedo (1974, p. 53-4) apresenta a palavra velhice, situada na seção tempo, dentro da classe relações abstratas, nos seguintes termos:

128. Velhice $=$ cardo extremus, velhez, ancianidade, anciania (ant.), senescência, senilidade, caducidade, caduquez, decrepidez, decrepitude, sênio (desus.), sol-pôsto, último quartel da vida, a última estação, a estação das neves, segunda infância; idade avançada, provecta, grave, em que o sangue gela nas veias; fardo da velhice; inverno da vida, da idade; o pêso (sic) dos anos, de muitos janeiros; anos provectos, maturidade, idade madura, fase climatérica da vida; última quadra, outono, crepúsculo da vida; declínio da existência, canície, cãs, neve, braneas; cabelos brancos, nevados; anadema (ant.); cara de pergaminho, de jenipapo maduro (pop); rosto (encarquilhado 256); passos vacilantes, arrastamento dos pés (vagareza) 275; fraqueza 160; perigalho, pelhancas, pelhancaria, pelharanca, pelanga, menopausa, melasmo, traspés, gerocômio ou gerontocômio; senioridade, velho 130.

V. envelhecer, ir em decadência; ficar, tornar-se, fazer-se velho; ser de anos já maduros, avelhentar-se 124; carregar o pêso (sic) dos janeiros, ser uma ruína do que foi, murchar-se a beleza, o acabar-se, estar acabado, estar com os pés para a sepultura, estar um caco, estar com um pé na cova, render-se aos anos; arrastar os pés (vagareza) 275; estar um podão, já estar com a memória obliterada (esquecimento) 506; tender para a decrepitude, decrepitar-se, abordar-se trêmulo ao cajado (fraqueza) 160; adiantar-se 
em anos, maturar-se; estar no seu quarto minguante, perto do seu ocaso; já estar chegando ao têrmo (sic) fatal, ter caruncho, carunchar, caducar, tremelicar (frio) 383 [...].

Adj. velho, idoso, vedro, dioso (ant.), antigo 124; ancião, senil, anil, caduco, cadivo, decrépito, tarouco, valetudinário, morredouro, envelhecido, avelhentado, anoso; avançado, entrado em anos; pesado, confecto, cheio de anos; qüinquagenário, sexagenário, setuagenário, ocotogenário, nonagenário, macróbio, revelho, revelhusco, chegado à idade provecta, carifranzido, anodonte, trôpego, trêmulo, tremelicoso, zoupeiro, alquebrado, quebrantado, abatido, infracto, venerando, patriarcal, matronal, jubilado, reformado, aposentado, emérito, grandevo, longevo, reumático, rabugento, de barbas nevadas, barbicano (poét.), ancestral, frescalhão, frescalhota, sênior, pai climatérico, aprico = que gosta de se aquecer ao sol; escanado.

Adv. Antigamente \& adj.; in processa aetate = em idade avançada.

A velhice, tal qual caracterizada no dicionário de Azevedo (1974), está fundada em uma concepção de fase da vida humana na qual o homem está incapacitado para a produção e para o trabalho. Desse modo, não desfruta e não pode desfrutar de um status social. Por outro lado, a velhice está, ainda, marcada pela ênfase nas limitações físicas, o que causa ou provoca pouca condição produtiva sob o ponto de vista comportamental, e até nas deficiências mentais, baseada na Psicologia do Excepcional, conforme atestam Araújo e Carvalho (2004/2005).

Diante disso, indagamos: o que esperar da convivência com um ser humano tão enfraquecido, abatido, empobrecido, próximo do fim, em implacável declínio, senão uma experiência negativa qualquer e até mesmo o contágio por essa decadência? Ante uma significação social tão negativa da velhice, não é para menos o tratamento dado e recebido por muitos indivíduos idosos.

Dicionários escolares também não escapam ao tom depreciativo. Bueno (1981, p. 582), por exemplo, em seu dicionário escolar da língua portuguesa, traz para o termo idoso os seguintes sinônimos: "adj. Velho, avançado em anos". Para o adjetivo velho, consta: "[...] Antigo; com muito tempo de existência; aveIhantado: gasto pelo uso; muito usado; que há muito possui certa qualidade ou exerce certa profissão; desusado; antiquado; s.m. homem idoso (aum.: velhacas; dimin.: velhinho, velhito, velhote, velhusco, velhustro)" (BUENO, 1981, p. 1185).

No que toca ao termo velhice, este é apresentado por Bueno (1981, p. 1185, grifo nosso) como: "s.f. Estado ou condição de velho; idade avançada; as 
pessoas velhas; rabugice própria de velho". Para a palavra envelhecer, consta: "v.t. Avelhantar; encanecer" (BUENO, 1981, p. 422). Avelhantar sinonimiza "v.t. Tornar velho prematuramente; fazer parecer velho, antiquado; $p$. fazer-se velho; perder o viço, o vigor" (BUENO, 1981, p. 154, grifo nosso). Já encanecer sinonimiza: "v.t. Ter cabelos brancos, cãs; envelhecer" (BUENO, 1981, p. 404).

Observamos que tanto em Azevedo (1974) quanto em Bueno (1981) os termos idoso e velhice estão sinonimizados de modo negativo e depreciativo. No entanto, como entender a produção atual de várias denominações atribuídas à velhice?

Recentemente - a partir da década de 60 do século XX -, assistimos à "criação" de inúmeras denominações designativas ao ser humano idoso, em uma busca frenética de contraposição às desqualificações que foram impostas a partir de determinadas idades.

Não sem razão, há pouco tempo, a sociedade passou a empregar e usar, exaustivamente, expressões como: terceira idade, melhor idade, maior idade, idade madura, feliz idade, evitando-se, ao menos de maneira formal, o termo idoso e velho, peremptoriamente rejeitado. No entanto essas expressões ou terminologias estão aí produzidas na sociedade e com intenções explícitas e não explícitas, em virtude do preconceito, para alguns; em razão de interesses econômicos, para outros.

Tomamos apenas um exemplo para explicitar quais são os interesses presentes nos diversos termos que procuram romper com as denominações velho e idoso, porque estão prenhes de preconceito. TROISIĖME ÂGE, ou seja, Terceira Idade, em língua portuguesa, foi uma expressão cunhada pelo gerontologista francês Jean-Auguste Huet, de acordo com Haddad (1986), cuja idade cronológica coincidia com a aposentadoria, entre a faixa de 60 e 65 anos. O termo foi publicado pela primeira vez em 1962, na revista Informations Sociales, que, naquela oportunidade, publicou um número aos aposentados, de modo acolhedor, conforme nos indica Lendzion (2002).

A expressão surge em um contexto francês de aumento da população idosa e que precisou formular uma política social voltada para a velhice. Era necessário, naquele momento, mudar a imagem das pessoas idosas, era necessário dar prestígio aos aposentados.

Essa expressão ganha força na década de 70 do século XX com a criação das Universidades da Terceira Idade - Universités Du Troisième Age -, e da mesma 
forma ocorre a sua incorporação no vocabulário anglo-saxão, com a expressão third age e a criação, em Cambridge, na Inglaterra, das Universities of Third Age (DEBERT, 1999).

O termo Terceira Idade passa a expressar, também, mudanças nos padrões de comportamento da geração que se aposenta e envelhece, mas ativamente. Esse parece ser o tom que a sociedade capitalista pretendeu dar com todas as forças para esse grupo, antes considerado senil, decrépito, não consumidor.

As denominações Terceira Idade e Melhor Idade, de acordo com os estudos de Campos (2003, p. 4), vêm "[...] para qualificar indivíduos com idade a partir de 50 anos e mais, considerando serem denominações de marketing usuais nos contextos mercadológicos direcionados a esta faixa etária, inserindo-se aí o mercado turístico", isto é, lazer direcionado aos potenciais consumidores desse tipo de serviço. A autora traz, ainda, uma interessante análise comparativa sobre o termo, realizada por Coriolano (2002 apud CAMPOS, 2003, p. 48, grifo nosso), em nota de rodapé de sua dissertação de mestrado, do seguinte modo: "[...] essa expressão associa-se ao termo terceiro mundo, que, por sua vez, associa-se à expressão terceiro estado da Revolução Francesa. Segundo a autora, isto é carregado de grande preconceito, remetendo ao descartável, ao improdutivo, ao que não interessa ao capitalismo, que vê o próprio homem como mercadoria".

De acordo com Mazo, Lopes e Benedetti (2001), no Brasil, essa expressão foi empregada pelo Serviço Social do Comércio (SESC) de São Paulo, ao serem criadas as denominadas "Escolas Abertas para a Terceira Idade", e, naquele momento, buscava-se apresentar a velhice com uma nova roupagem, isto é, como uma nova etapa na vida dos homens.

Anita Liberasso Neri concedeu entrevista ao jornal eletrônico ComCiência, em 2002, e, ao ser indagada sobre como os idosos deveriam ser chamados, diante de tantas denominações que Ihes são atribuídas, esta estudiosa da Gerontologia assim responde:

Eu acho que podemos chamar de idosos mesmo. A expressão terceira idade é um eufemismo. Ela foi inventada porque as pessoas rejeitam o nome velho ou idoso e então resolveram que terceira idade é mais bonito, o que denota tanto preconceito quanto outros nomes como bela idade e maior idade entre outros menos usados, mas todos com o mesmo sentido. O termo terceira idade foi cunhado na França na década de 60, quando aquele país começou a fazer investimentos no lazer das pessoas acima de 45 anos, porque achavam que se 
as pessoas ficassem ativas, envelheceriam melhor, mais satisfeitas e saudáveis. Isso parecia mais conveniente para o sistema de saúde, para as finanças do Estado e para a sociedade em geral. Começaram a criar cursos, oportunidades educacionais e alternativas de lazer, entre outras atividades para os adultos mais velhos, recém-aposentados, e chamaram essa fase da vida de terceira idade no intuito de estimular a participação de pessoas que se viam e eram vistas como inativas e improdutivas. Cada país cria o seu léxico para lidar com a velhice, da mesma forma como com outros temas considerados difíceis. Por exemplo, hoje, em certos contextos, não se deve mais falar negro, e sim afro-americano, não se deve falar em deficiente, e sim pessoa portadora de deficiência, ou em diversidade de opção sexual em vez dos nomes tradicionais, e assim por diante. Na verdade, são nomes dados para evitar a discriminação, mas se você não resolver os problemas que originam essa discriminação, não adianta nada. Assim, a crítica que eu faço sobre a invenção da expressão terceira idade é que esconde [a] negação da velhice e rejeição dos idosos. Alem disso, junto com a nova denominação são disseminadas falsas crenças sobre a velhice, apontada como fase que pode ser evitada e, o que é pior, que isso é apenas uma questão de responsabilidade pessoal (grifo nosso).

Siqueira, Botelho e Coelho (2002, p. 904) trazem, também, suas contribuições para a desmistificação do termo Terceira Idade, ao considerar que ele "[...] é uma construção das sociedades contemporâneas e vem sendo empregado por acreditar-se que é isento de conotações depreciativas", quando, de fato, não é.

Acreditamos que a criação dessa expressão acomoda as pessoas que se encontram em uma faixa etária que desfruta de boas condições de saúde, disposição física e disponibilidade de tempo para aproveitar novas experiências. A expressão visou e conseguiu atingir seus objetivos, atender aos interesses do capital, isto é, de um mercado de consumo emergente, cada vez mais concorrido e disputado, em especial, a área do lazer.

Mesmo diante de todas essas infiltrações, invenções e modismos, o significado social de idoso e de velhice permanece, ainda, depreciativo. E por quê? Consideramos que em uma sociedade na qual se valoriza a juventude e a ela está associada a ideia de produtividade, vigor, alegria, prazer, beleza, sucesso, saúde, potencial, a imagem do indivíduo idoso remete à noção de improdutividade, cansaço, apatia, tristeza, impotência, doença ou saúde frágil, entre outras associações negativas.

Em conformidade com o que afirmamos anteriormente, assistimos a uma investida publicitária e comercial sobre os indivíduos idosos, mas não todos. Por 
suposto, isso está associado ao aumento do envelhecimento populacional, o que, naturalmente, gera maior número de pessoas que se encontram na condição de idosos, muitos deles considerados consumidores potenciais, isto é, com dinheiro em mãos, em razão de suas aposentadorias e de suas condições financeiras. Os holofotes direcionados aos idosos não são gratuitos nem fortuitos.

A velhice vem se convertendo, ao longo da terça última parte do século XX, em um nicho de mercado a ser explorado. Trata-se de um grupo (dos saudáveis e com disposição e disponibilidade) que é elevado à condição de consumidor em potencial e, em certos casos, com muito potencial e com muito poder econômico. O idoso, neste caso, assume a condição, em primeiro lugar, de cliente, consumidor; consequentemente, não pode ser tratado como velho, quer dizer, como senil, decrépito, de memória obliterada, rabugento, reumático.

A despeito da intencionalidade comercial sobre o idoso, temos de reconhecer que, ao se retirar da penumbra a velhice, abre-se a possibilidade de discussão e enfrentamento do preconceito ao idoso que por tanto tempo está vigorando, de forma banalizada e anistórica.

\section{PRECONCEITO AO IDOSO SOB UMA PERSPECTIVA HISTÓRICO- CULTURAL}

Ainda que a velhice se torne pauta de discussão e objeto de ações, inclusive de políticas públicas, ela ainda não é entendida como continuidade do desenvolvimento humano, desde que sejam, evidentemente, oferecidas ao indivíduo condições para tal. Ela continua a ser tomada de uma perspectiva decadente, tal como é apresentado pelo léxico, cabendo ao indivíduo idoso o ônus de sua idade avançada e o preconceito.

A propósito do preconceito, cremos que ele esteja relacionado à naturalização da velhice. É como se leis biológicas dirigissem o processo de desenvolvimento do homem idoso, desenvolvimento esse reduzido ao envelhecimento orgânico.

Consideramos, aqui, o desenvolvimento humano como fruto da relação apropriação-objetivação. E o que isso significa? Objetivação e apropriação são duas categorias, delimitadas por Duarte (1993), na obra A individualidade para-si: contribuição a uma teoria histórico-cultural da formação do indivíduo, para a reflexão sobre o processo de formação do ser humano. Tais categorias expressam a dinâmica do processo de autoconstrução do ser humano ao longo da história. 
A objetivação é definida como o processo de produção e reprodução da cultura humana, da vida em sociedade; já a apropriação diz respeito àquilo que o indivíduo internaliza, de acordo com as circunstâncias, das elaborações humanas objetivadas e que passa a compor suas características singulares.

Nessa perspectiva, conseguimos entender que aquilo que o indivíduo se torna não está determinado a priori, assim como não está determinado o fim de seu desenvolvimento em virtude da idade avançada. A velhice, nesse sentido, é entendida como continuidade do processo sempre inconcluso de desenvolvimento do ser humano.

Tomar a velhice como decadência, decrepitude inevitável, é naturalizar a existência do homem, é explicá-la apenas sob uma perspectiva - a biológica. Essa explicação reduz a vida humana a três momentos: nascimento, crescimento e morte. Ao generalizar e naturalizar a velhice, esvazia-se o que é o humano, o que é o seu desenvolvimento regido por leis sócio-históricas, tornando-o uma abstração.

Se o processo de envelhecimento é natural ao ser humano, faz parte de seu desenvolvimento e é regido por leis biológicas, o menor valor atribuído ao indivíduo idoso, à velhice, o preconceito que lhe é desfechado, é, fundamentalmente, histórico. Com isso queremos dizer que aquilo que o indivíduo é ou será em sua velhice depende das apropriações das objetivações humanas, que vão do nascimento até a morte.

Tal afirmação está respaldada nos fundamentos da teoria histórico-cultural, precisamente ao postular que a formação de características humanas em cada indivíduo, seja ele jovem, seja ele idoso, desenvolve-se

[...] não a título de aptidões inatas, não a título de adaptação do comportamento específico aos elementos variáveis do meio, mas é o produto da transmissão e da apropriação pelos indivíduos das aquisições do desenvolvimento socio-histórico (sic) e da experiência das gerações anteriores. (LEONTIEV, 1978, p. 188).

Explicado de outro modo, significa que é preciso que todo e qualquer indivíduo se aproprie das experiências e aquisições da humanidade, uma vez que, "[...] as aptidões e caracteres especificamente humanos não se transmitem de modo algum por hereditariedade biológica, mas adquirem-se no decurso da vida por processo de apropriação da cultura criada pelas gerações precedentes" (LEONTIEV, 1978, p. 267). 
Faz-se necessário, então, que todo e qualquer indivíduo se aproprie, no decorrer de sua vida, do nascimento até a morte, mesmo durante a sua velhice, da atividade humana encarnada nos objetos e fenômenos sociais, ou melhor, encarnada na cultura humana.

Sem dúvida a velhice, para muitos, é privação, é sofrimento, é marginalização, é definhamento. Para outros, no entanto, é continuidade da vida, continuidade do processo de apropriação e objetivação, é continuidade do trabalho que os fazem humanos, independentemente da idade. Tomamos os exemplos de Maciel e Taam (2007) e ilustramos essa concepção de velhice como continuidade com homens como Georges Snyders, um clássico da área da educação que aos 88 anos brindava-nos, em 2005, com mais um livro; Norberto Elias, autor da área das Ciências Sociais, que escreveu vários livros após completar seus 80 anos; Oscar Niemeyer, cujo “[...] trabalho de artista/arquiteto atravessa os tempos e atrai sobre si os olhares do mundo" (MACIEL; TAAM, 2007, p. 61). O que queremos marcar aqui é que esses homens, como tantos outros, produziram e produzem preciosidades em suas velhices.

Chegar à velhice como um indivíduo ativo, produtivo, criativo, em pleno processo de humanização, objetivando-se de modo mais e mais humano, assim como viver de modo improdutivo, à espera da morte, não é determinação de leis biológicas. Não podemos nos esquecer de que muitos indivíduos idosos precisam buscar o sustento, por meio de seu trabalho, até o limite da força física e, em muitas ocasiões, até a morte.

Não podemos negar que o homem, em seu processo de envelhecimento, portanto, de desenvolvimento, vivencia alterações de algumas funções orgânicas. Elas, de fato, existem e fazem parte do processo de envelhecimento. Entretanto não podem, em si, ser determinantes daquilo que o homem idoso é. O que determina a existência na velhice é aquilo que circula no contexto em que a pessoa vive e de que ela se apropria.

Tomar o idoso de forma generalizante, como se fosse uma figura abstrata, sem materialidade, desconsiderando as diferenças entre os indivíduos pertencentes às diferentes classes sociais, as quais decorrem das diferentes formas de inserção social, é, no mínimo, problemático. Da mesma forma, consideramos que seja problemático generalizar o preconceito ao idoso.

A existência do preconceito é concreta, é real, está aí, porém precisamos questionar contra quem ele recai, sobre qual idoso. Certamente não é dirigido ao 
idoso Oscar Niemeyer, ao idoso Georges Snyders e outros indivíduos igualmente idosos e em plena atividade intelectual, artística, física etc.

Entendemos que, para combater o preconceito ao idoso, é fundamental precisar, exatamente, quem é o homem que o sofre, que o desfecha, senão tendemos a voltar-nos a uma abstração. Conhecer o idoso real é, em nosso entendimento, condição sine qua non para ações de efeito e não meramente paliativas ou inócuas.

Ao naturalizar a velhice, porque vem associada à fragilidade, vulnerabilidade, apatia, dependência, doença, disponibilidade para tarefas domésticas, hipocondria, entre outros aspectos e fatores, naturalizamos também a compreensão que temos dela. Sob uma perspectiva naturalizante, cabe-nos aceitar, e de preferência isentos de preconceito, a situação "natural" de que o idoso é decadente, teimoso, ranzinza, retrógrado, estagnado, ou seja, este é o caminho natural dos seres humanos ao adentrar a velhice.

Como inibir, coibir, censurar o preconceito, se não rompemos com a visão naturalizada daquilo que é histórico, isto é, a condição humana, também aberta ao idoso? Esta nos parece, ainda, uma questão que precisa ser discutida, refletida por nós, pelos nossos pares, pela academia, porque é sempre necessária, sempre premente, sempre humana.

\section{CONSIDERAÇÕES FINAIS}

O envelhecimento populacional tem se tornado, ano após ano, uma realidade, e não mais uma projeção para o futuro. Não se trata mais de possibilidades, de apresentar dados estatísticos, mostrando o que poderá ocorrer no futuro. Ele não faz mais parte do futuro; ele é presente.

Em razão do estado presente e do caráter inédito desse cenário - baixa fecundidade e aumento da expectativa de vida contrapondo-se ao aumento significativo da população idosa -, vêm sendo lançados, à sociedade civil e suas instituições, desafios de como administrar essa situação. Esse desafio tem de se dar sob os efeitos de uma forma societária, na qual o que está em questão é o lucro, e não o bem-estar do ser humano, a potencialização de seu desenvolvimento, independentemente de idade, sexo, etnia, região, religião etc.

De acordo com os estudos de Siqueira, Botelho e Coelho (2002, p. 900), a Organização das Nações Unidas (ONU) denominou o período de 1975 a 2025 como "Era do Envelhecimento". Estamos, por conseguinte, vivendo exatamente essa 
era. Por outro lado, os censos do IBGE vêm revelando aumento considerável do número de idosos no Brasil, estimando-se que, ao alcançarmos a primeira década do século XXI, teremos em torno de 9,2\% de idosos entre a população brasileira. Será essa população preterida, marginalizada, excluída, em sua maioria? Os benefícios deste século serão alcançados por qual grupo de idosos? E os demais?

É nessa esteira que campanhas oficiais alardeiam o desafio dessa situação nova: proclama-se a valorização do idoso e a inibição do preconceito contra ele; lança-se o Plano de Ação Governamental Integrado para o Desenvolvimento da Política Nacional do Idoso; cria-se o Estatuto do Idoso; institui-se o Dia Nacional do Idoso (27/09/1992) e o Ano Internacional do Idoso (1999).

Na sociedade da velocidade, do instantâneo, do fugaz, do transitório, da valorização do novo, do último lançamento, não é o ritmo do indivíduo idoso, a sua sabedoria ou o seu longo exercício de viver que determinam ou definem a ordem e a intensidade das relações. É por essa razão que ele é depreciado, infantilizado, a não ser quando está na condição e no papel de consumidor.

O envelhecimento como processo biológico, como alteração de algumas funções orgânicas, como parte do desenvolvimento biológico do homem, é real, está posto para todos os seres humanos e não há como negá-lo. No entanto é preciso entender que a velhice com caráter negativo é fenômeno social, logo, produção humana, erigida no interior das relações sociais sobre a base material da vida.

A promoção do indivíduo idoso exige-nos clareza do que seja o ser humano e o que ele pode tornar-se e, nessa perspectiva, acreditamos que a teoria histórico-cultural tem muito a contribuir com essa discussão; em especial, no processo de formação escolar.

\section{REFERÊNCIAS}

ARAÚJO, L. F.; CARVALHO, V. A. M. L. Aspectos sócio-históricos e psicológicos da velhice. MNEME - Revista de Humanidades, Caicó, RN, v. 6, n. 13, p. 1-9, dez. 2004/jan. 2005.

AZEVEDO, F. F. S. Dicionário analógico da língua portuguesa (idéias afins). Brasília: Editora de Brasília, 1974.

BOCK, A. M. B. A perspectiva sócio-histórica de Leontiev e a crítica à naturalização da formação do ser humano: a adolescência em questão. Cadernos Cedes, Campinas, SP, v. 24, n. 62, p. 26-43, abr. 2004. 
BUENO, F. da S. Dicionário escolar da língua portuguesa. 11. ed. Rio de Janeiro: FENAME, 1981.

CAMPOS, T. J. Lazer e terceira idade: contributos do turismo no âmbito do Programa Clube da Melhor Idade. 2003. 151 f. Dissertação (Mestrado em Gerontologia)- Universidade Estadual de Campinas, Campinas, 2003.

DEBERT, G. G.. A reinvenção da velhice: socialização e processos de reprivatização do envelhecimento. São Paulo: EDUSP, 1999.

DUARTE, N. A individualidade para-si: contribuição a uma teoria histórico-social da formação do indivíduo. Campinas, SP: Autores Associados, 1993.

HADDAD, E. G. de M. A ideologia da velhice. São Paulo: Cortez, 1986.

LENDZION, C. R. Envelhecimento e qualidade de vida. Revista Pró-Saúde, Curitiba, PR, v. 1, n. 1, 2002.

LEONTIEV, A. O desenvolvimento do psiquismo. Lisboa: Livros Horizonte, 1978.

MACIEL, A. T. B.; TAAM, R. A velhice como espetáculo. Acta Scientiarum, Maringá, v. 29, n. 1, p. 57-62, 2007.

MAZO, G. Z.; LOPES, M. A.; BENEDETTI, T. B. Atividade física e o idoso: concepção gerontológica. Porto Alegre: Sulina, 2001.

MINAYO, M. C. S. Violência contra idosos: relevância para um velho problema. Cad. Saúde Pública, Rio de Janeiro, v. 19, n. 3, p. 783-91, maio/jun. 2003.

NERI, A. L. Gerontologia estuda envelhecimento de forma global. Entrevista realizada em 10 set. 2002. Disponível em: http://www.comciencia.br/entrevistas/envelhecimento/neri. htm. Acesso em: 4 ago. 2008.

SIQUEIRA, R. L.; BOTELHO, M. I. V.; COELHO, F. M. G. A velhice: algumas considerações teóricas e conceituais. Ciência \& Saúde Coletiva, Rio de Janeiro, v. 7, n. 4, p. 899-906, 2002.

\section{Sobre os autores:}

Renata de Almeida Vieira: Professora do Instituto Federal de São Paulo (IFSP). Doutorado em Educação pela Universidade Estadual de Maringá (UEM). E-mail: realvieira@gmail.com, ORCID: http://orcid.org/0000-0003-3285-4783 
Lizete Shizue Bomura Maciel: Doutora em Educação pela Pontifícia Universidade Católica de São Paulo (PUC-SP). E-mail: revipereira2013@gmail.com, ORCID: http://orcid.org/0000-0003-2375-975X

Recebido em 18 de julho de 2019.

Aprovado em 18 de dezembro de 2019. 
